\title{
Knowing Means Existing: Organizational Learning Dimensions and Knowledge Management Capability
}

\author{
Lejla Turulja, Nijaz Bajgorić \\ School of Economics and Business Sarajevo, Sarajevo, Bosnia and \\ Herzegovina
}

\section{Abstract}

Background: Many studies have considered knowledge as the most important strategic resource for ensuring firm's competitiveness. Accordingly, learning is an important concept for firms whether it is individual or organizational learning. Objectives: To provide empirical support to the impact of individual organizational learning dimensions on a firm's knowledge management. Methods/Approach: The questionnaire survey approach is used for data collection and structural equation modeling for hypotheses testing. Besides, PROCESS procedure is employed to estimate confidence intervals of indirect effects in the model. Results: Organizational learning dimensions are antecedents of knowledge management capability. Shared values and openness influence directly and positively knowledge management capability. However, the same was not found to be the case for managerial commitment and dialogue. On the other hand, the results suggest that managerial commitment and dialog influence knowledge management capability indirectly over shared vision. Conclusions: While there has been an underlying assumption about the role of organizational learning for knowledge management, this study provides evidence on how organizational learning dimensions such as management commitment, shared vision, openness and experimentation, and dialog may be adjusted to facilitate and enhance knowledge management processes.

Keywords: Knowledge Management; Organizational Learning; Managerial Commitment; Shared Vision; Experimentation; Dialog

JEL classification: D83

Paper type: Research article

Received: Nov 19, 2017

Accepted: Feb 16, 2018

Citation: Turulja, L., Bajgorić, N. (2018), "Knowing Means Existing: Organizational Learning Dimensions and Knowledge Management Capability", Business Systems Research, Vol. 9, No. 1, pp. 1-18.

DOI: 10.2478/bsrj-2018-0001

\section{Introduction}

Business globalization and rapid technology development increase the pressure on firms to continuously change, improve and adapt to changing and dynamic 
business environment. Because of the rapid globalization, the value of managing their intangible assets as a core ability for business success became of crucial importance for firms. Organizational business performance is increasingly a function of firm's ability to develop and implement unique and valuable resources that cannot be easily imitated by competition. Barney (1991) has identified four characteristics of resources essential to gaining a sustainable competitive advantage: (1) the resource must be valuable (valuable - V); (2) must be rare (rare R); (3) must be difficult to imitate (inimitable - 1); (4) must be irreplaceable (nonsubstituted - N). This idea is known as the VRIN framework (Lockett et al., 2009). The theory whose basic idea lies in the contention that firm's performance differentiate due to the different resources and their utilization is Resource-Based View - RBV. The recent studies emphasize the difference between tangible assets, i.e., firm's physical capital and intangible assets, such as organizational routines and capabilities (Teece et al., 1997). Dynamic resources lie in the firm's ability to generate additional values through continuous improvement of existing resources.

Many studies have considered knowledge as the most critical strategic resource for ensuring firm's long-term survival and competitiveness since some forms of knowledge can be valuable, scarce and difficult to imitate (Donate et al., 2011). Knowledge may reside in people or firm's business-related activities and products/services (Chuang et al., 2013). Thus, learning is an important concept for firms whether it is individual learning or processes of organizational learning. Organizational learning has long been considered as one of the antecedents and measures of organizational business performance (Qi et al., 2018). Consequently, literature recognizes organizational learning (OL) capability and knowledge management (KM) capability as two essential capabilities for firms doing business in the knowledge-based economy (Dayan et al., 2017; Celemín-Pedroche et al., 2017). In other words, knowledge is the main strategic resource and the main strategic mean is organizational learning (Liao et al., 2009). Thus, this study draws on dynamic capability view and organization theory to clarify the nature of the relationships between OL capability and KM capability. The main objective of this study is to analyze the theoretical and empirical relationship between OL and KM capability.

There are several contributions of this paper. First, this study develops a comprehensive model that features knowledge management capability and organizational learning capability as antecedents of organizational business performance considering the relationship between them. In addition, some authors analyzed KM as an antecedent of OL (Liao et al., 2009), while Noruzy et al. (2013) confirmed that organizational learning directly and positively influenced knowledge management. Therefore, the understanding of the rationale behind this relationship and its empirical confirmation will elucidate the gap in the literature. Second, the impact of individual OL processes on KM is addressed. While organizational learningknowledge management relationship has been investigated, individual dimensions of OL as antecedents of KM have not previously been analyzed in a configurational model of organizational business performance. Since dimensions of OL capability could be implemented and exist separately, it is important to analyze whether separate $\mathrm{OL}$ constructs affect $\mathrm{KM}$ as well. By isolating their individual impacts on knowledge management capability, a better understanding of the relative significance of separate organizational learning processes is provided. Third, this study attempts to find the interplay between organizational learning capability dimensions, i.e., between managerial commitment, shared vision, openness and experimentation, and dialog in the same structural model with knowledge management. Confirming the interrelationships between dimensions of 
organizational learning capability allows a better understanding of the antecedents of organizational knowledge acquisition. This helps to understand how firms can improve organizational learning processes and thus to advance its strategic resources. This model so far is one of the most comprehensive frameworks of the relationship between organizational learning and knowledge management.

The paper is structured as follows. First, theoretical foundations of the study are presented. Then, concepts of organizational learning and knowledge management are briefly explained, as well as proposed conceptual model and hypotheses. Third, methodological approach, as well as the process of data collection, are introduced. Finally, data analysis, discussion and study conclusions are presented.

\section{Literature Review}

\section{Theoretical Foundation}

The theoretical foundations for this study are Dynamic Capability View (DCV) and Organization Theory (OT). DCV is grounded in the research efforts to answer the question "What resources and capabilities have an impact on firm's business performance?". McKeown et al. (2003) stated that contemporary firms operate in a time of fundamental and accelerated changes that are characterized by business and market globalization and the ubiquity of information technology. They highlighted the quote that It is not the strongest that survive, nor the most intelligent, but most adaptive (McKeown et al., 2003). Teece et al. (1997) noted that only those firms that have the ability of efficient coordination and redistribution of internal and external capabilities and resources in order to timely respond to the needs and demands of the market could be competitive at the global market. Consequently, they presented a theory of dynamic capabilities based on the assumption that firms which own and continuously improve, expand and configure its resource base in creating dynamic capabilities will be able to achieve a sustainable competitive advantage. Literature recognizes different dynamic capabilities that are critical for contemporary firms with the knowledge being one of the most important for firms operating in knowledge-based economy (Pun et al., 201 1; Apak et al., 2012; Nezam et al., 2016; Martinez-Conesa et al., 2017).

Organization theory is characterized by its diversity of approaches resulting in multiple schools of thought (Sailer et al., 2010; McKinley et al., 1999). There are many approaches to organization theory, but the primary object is broadly defined as "organization", which includes different kinds of organizations as well as organizational activities and processes. Hatch et al. (2013) discussed three perspectives of organization theory. First, modern perspective focuses on discovering the universal principles and laws that govern organizations, and it emphasizes structure, rules, standardization, and routine. Second, symbolic perspective describes how life evolves within organizations in rituals and other activities and processes in order to gain insight into how organizing occur. Finally, postmodern perspective puts emphasis on the evaluation and deconstructing organizational texts in order to discover managerial ideologies and subvert modernist modes of organizing and theorizing. McKinley et al. (1999) pointed out that most of the theorists in organization theory focus on the way how firms perform the business; specifically, the processes that are used in generating organizational knowledge. Two management disciplines address the knowledge in the firm: i) organizational learning, and ii) knowledge management.

In the light of the discussion, this study draws on organization theory and its modern perspective, in order to discover and explain the principles regarding the 
relationships between the processes of organizational learning and knowledge management. In addition, it draws on dynamic capability view to analyze the impact of OL and KM capabilities on the organizational business performance.

\section{Organizational Learning Capability}

Knowledge has been recognized as a critical resource of contemporary organizations where knowledge is seen as "a knowledge of the individual" or "collective knowledge". Collective or organizational knowledge comes from the integration of knowledge; it is a combination of coordinated efforts by several individuals who have different but complementary skills (Grant, 1996). Organizational knowledge exists in firm's documents and systems for data storage, as well as in the routines and processes. Therefore, organizational knowledge is the result of the organizational learning processes, which involves processes that range from the level of the individual to the level of the group and the firm, and back (Jerez-Gómez et al., 2005). In other words, organizational learning is a process through which firms learn (Alegre et al., 2008). Organizational learning is one of the key determinants of business performance of the contemporary firm. OL capability refers to a set of factors that influence the firm's tendency to learning, i.e., organizational learning can be understood as set of processes, while learning capability refers to those characteristics that make it possible for firms to learn (Prieto et al., 2014; LópezCabrales et al., 2011). In other words, organizational learning capability refers to organizational and managerial attributes that ease and facilitate the organizational learning process or allow an organization to learn (Chiva et al., 2007).

OL capability is conceptualized as a multidimensional construct with the following dimensions: managerial commitment; shared vision; openness and experimentation; and dialog (Calantone et al., 2002; Chiva et al., 2007).

- Managerial commitment refers to the management attitudes that promote and motivate innovative organizational culture as well as individual learning that presents the first step towards organizational learning.

- Shared vision/system perspective relates to the gathering of all employees around a common identity and a shared vision.

- Openness and experimentation imply organizational culture and climate that promote acceptance of new ideas and attitudes as well as tolerance of ambiguity, uncertainty, and errors. It promotes creating an environment that allows risk-taking.

- Dialog relates to continuous collective involvement in the processes, assumptions, and beliefs that make every day experiences.

\section{Knowledge Management Capability}

Many authors have investigated the importance of successful knowledge management in a firm, and the general conclusion is that, in order to maintain their competitive advantage in a dynamic environment, firms must develop the knowledge management capability, i.e. the dynamic capability to create and modify knowledge over time (Chen et al., 2013). In other words, individual knowledge of employees is not a sufficient prerequisite for firm's success. Employees should apply their knowledge to business processes in order to create additional value for a firm. In addition, individuals should share their knowledge to create conditions for the knowledge integration and its continuous upgrade. For this reason, KM represents set of processes critical for the knowledge acquisition, its integration, upgrade, and application. Davenport et al. (1997) state that most of the knowledge management processes have one of the following three objectives: (i) to make 
knowledge visible and emphasize the role of knowledge in the firm; (ii) to develop a culture that will encourage the acquisition and sharing of knowledge; and (iii) to build a knowledge infrastructure, which includes the IT system and network to enable communication and encourage cooperation. Therefore, knowledge management refers to the processes of acquisition, conversion, and application of knowledge. The main objective of the knowledge management capability is to explore, assimilate, and exploit knowledge taking into account both internal and external knowledge sources (Chen et al., 2013).

KM capability is conceptualized as a multidimensional construct with following dimensions: knowledge acquisition; knowledge conversion; and knowledge application (Liao et al., 2009).

- Knowledge acquisition refers to the processes that seek and acquire knowledge and create new knowledge, i.e., processes of obtaining and accumulating knowledge (Cui et al., 2005).

- Knowledge conversion is related to the processes of making existing knowledge useful. Processes that are included in the conversion are organization, integration, coordination, and dissemination of knowledge (Cui et al., 2005).

- Knowledge application refers to the processes of using knowledge. Cui et al. (2005) noted that these processes include storage, retrieval, contribution, application, and knowledge sharing.

\section{Theoretical model and hypotheses}

Organization Learning Capability and Knowledge Management Capability

A literature review has been conducted in order to recognize the relationship between OL capability and KM capability. Organizational learning is grounded in individual learning (Pun et al., 2011). OL derives from the knowledge acquisition of the individual employees and grows through the exchange and integration of the knowledge until a collective knowledge corpus is established (Jerez-Gómez et al., 2005). These processes should be embedded in the organizational culture. Thus, management should be committed to the creation of such organizational culture that promotes learning, experimentation, dialogue and shared values. In other words, OL could be considered as a climate and culture that promote these values. At the other side, knowledge management refers to the processes that help organizations to find, select, organize, disseminate, transfer and use knowledge within the organization (Pun et al., 2011). In other words, OL supports and encourages employees' learning while KM identifies their knowledge and collects it into an organizational knowledge corpus. Organizations would not be able to manage knowledge if it does not exist, and the assumption of the existence of knowledge is the climate of organizational learning. This interaction between the $\mathrm{OL}$ and $\mathrm{KM}$ is presented in Figure 1. 
Figure 1

The process of organizational learning

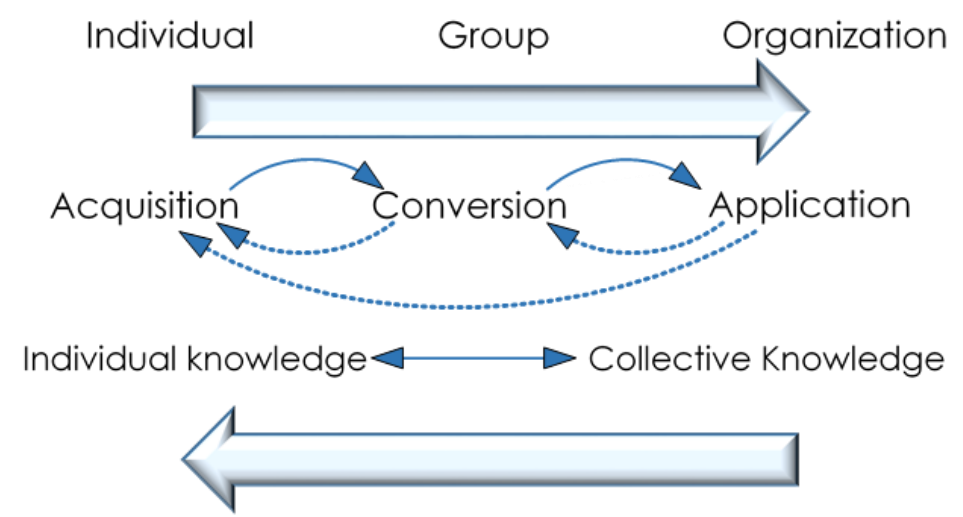

Source: Jerez-Gómez et al. (2005)

Based on the discussion, following hypothesis is proposed:

H1. OL capability positively influences KM capability. However, when it comes to the individual constructs of $\mathrm{OL}$ capability, there is a research gap related to their separate importance for the efficient KM. In other words, managerial commitment, shared vision, openness and experimentation, and dialog are processes that represent the concept of organizational learning. However, these processes could be implemented separately. However, the question is: whether separate $\mathrm{OL}$ constructs affect KM positively as well? Since OL positively affects KM, it is reasonable to expect that all constructs individually would enhance KM as well.

Therefore, the following sub-hypotheses are suggested:

Hla. Managerial commitment positively influences KM capability.

$\mathrm{HI}$ b. Shared vision positively influences KM capability.

Hlc. Openness and experimentation positively influence KM capability.

Hld. Dialog positively influences KM capability.

Organization Learning Capability / Knowledge Management Capability and Business Performance

Organizational learning supports both learning and innovative culture, which result in better organizational performance. $\mathrm{OL}$ is a critical antecedent of innovation in firms (Jerez-Gómez et al., 2005). The firms that learn faster and use knowledge most effectively are most likely to become and remain leaders (Pun et al., 2011). Knowledge is undoubtedly the most important resource of the knowledge-based economy and the most valuable resource that a firm can dispose of. The real differentiation among firms can be done based on learning and knowledge. Only firms that learn and generate knowledge can use it in the innovation of its products, services, and processes.

Following these premises, two hypotheses are proposed:

H2. OL capability positively influences organizational business performance.

H3. KM capability positively influences organizational business performance.

In addition, some previous studies have discussed the dimensions of $\mathrm{OL}$ and proposed their interplay. So, the concept of shared vision is considered a fundamental for the firm's success (Hodgkinson, 2002) and it is related to shared values and common goals and understanding in collective relationships. Managers should perceive the need for a shared vision and have the capacity to develop it amongst individuals within the organization. Thus, managerial commitment helps to 
apprise the sense of identity in individuals and may create dedication and commitment to the organization and its goals (Hodgkinson, 2002). Managers continually share their own vision by communicating and supporting communication. That is how shared vision could be achieved through dialogue and communication (Hodgkinson, 2002). Consequently, we pose the following hypothesis:

H4. Managerial commitment and dialogue have a positive impact on organizational shared vision.

However, in order to get a better understanding of relationships between $\mathrm{OL}$ dimensions and $\mathrm{KM}$, we have proposed following sub-hypotheses:

H4a. Managerial commitment positively influences shared vision.

H4b. Dialogue positively influences shared vision.

\section{Research Methodology}

Sample description

Primary data were collected using questionnaire methodology. The target population was small, medium and large firms operating in the market of Bosnia and Herzegovina. Respondents were general managers familiar with all organizational processes. The questionnaire consisted of indicators adopted from previous studies. After the first invitation to participate in the research sent by e-mail, we sent two reminders in the period of sixteen days. The e-mail included a link to a web-based survey and noted that results of the research would be presented summarily. The total number of observations to be analyzed by this paper is 403 (41.69\% of small, 41.92 of the medium, and 16.38 of large firms), which is $13.59 \%$ of the total number of sent calls. This response rate is satisfactory if we consider that the respondents were firms' managers, and previous research shows that the response rate in similar studies is in decline (Cycyota et al., 2002).

\section{Research instrument}

All multi-item measures used were based on seven-point Likert scales ranging from 1 - strongly disagree to 7 - strongly agree, with the following dimensions.

- OL capability is a reflective second order measurement model with four first-order dimensions: managerial commitment, shared vision, openness and experimentation, and dialog. It consists of fourteen indicators adopted from Calantone et al. (2002), Akgun et al. (2007) and Alegre et al. (2013).

- KM capability is a reflective second-order latent model with three first-order dimensions: knowledge acquisition, knowledge conversion, and knowledge application. It consists of thirteen indicators adopted from Liao et al. (2009).

- Organizational business performance is reflective first order construct of four indicators measuring organization's profit, sale, and return on investment comparing to main competitors as well as the realization level of the planned market share. Indicators are adopted from Chen et al. (2009).

- Firm size was used as control variable since larger firms may have a higher potential for exploiting knowledge (Tanriverdi, 2011) and achieve business success. 
Table 1

Research instrument description (Likert scale 1-7)

\begin{tabular}{|c|c|c|}
\hline Construct & Code & Item \\
\hline \multirow{5}{*}{$\begin{array}{l}\text { Knowledge } \\
\text { Acquisition } \\
\text { (KMA) }\end{array}$} & KMAl & $\begin{array}{l}\text { Our firm has processes for acquiring knowledge about our suppliers (and } \\
\text { customers). }\end{array}$ \\
\hline & KMA2 & Our firm uses feedback from projects to improve subsequent projects. \\
\hline & KMA3 & Our firm has processes for exchanging knowledge with our business partners. \\
\hline & KMA4 & $\begin{array}{l}\text { Our firm has process for acquiring knowledge about new product/services } \\
\text { within our industry. }\end{array}$ \\
\hline & KMA5 & Our firm has process for benchmarking performance. \\
\hline \multirow{4}{*}{$\begin{array}{l}\text { Knowledge } \\
\text { Conversion } \\
\text { (KMK) }\end{array}$} & KMKI & $\begin{array}{l}\text { Our firm has processes for absorbing knowledge form individuals into the } \\
\text { organization. }\end{array}$ \\
\hline & KMK2 & $\begin{array}{l}\text { Our firm has processes for absorbing knowledge from business partners into the } \\
\text { organization. }\end{array}$ \\
\hline & KMK3 & Our firm has processes for integrating different sources and types of knowledge. \\
\hline & KMK4 & Our firm has processes for replacing outdated knowledge. \\
\hline \multirow{4}{*}{$\begin{array}{l}\text { Knowledge } \\
\text { Application } \\
\text { (KMP) }\end{array}$} & KMPl & Our firm uses knowledge to improve efficiency. \\
\hline & KMP2 & $\begin{array}{l}\text { Our firm is able to locate and apply knowledge to changing competitive } \\
\text { conditions. }\end{array}$ \\
\hline & KMP3 & Our firm makes knowledge accessible to those who need it. \\
\hline & KMP4 & Our firm quickly links sources of knowledge in solving problems. \\
\hline \multirow{3}{*}{$\begin{array}{l}\text { Managerial } \\
\text { Commitment } \\
\text { (LM) }\end{array}$} & LM1 & $\begin{array}{l}\text { Managers basically agree that our organization's ability to learn is the key to } \\
\text { our competitive advantage. }\end{array}$ \\
\hline & LM2 & The basic values of this organization include learning as key to improvement. \\
\hline & LM3 & $\begin{array}{l}\text { The sense around here is that employee learning is an investment, not an } \\
\text { expense. }\end{array}$ \\
\hline \multirow[t]{4}{*}{$\begin{array}{l}\text { Shared Vision } \\
\text { (LV) }\end{array}$} & LV1 & $\begin{array}{l}\text { There is total agreement on our organizational vision across all levels, functions, } \\
\text { and divisions. }\end{array}$ \\
\hline & LV2 & All employees are committed to the goals of this organization. \\
\hline & LV3 & $\begin{array}{l}\text { Employees view themselves as partners in charting the direction of this } \\
\text { organization. }\end{array}$ \\
\hline & LV4 & $\begin{array}{l}\text { All parts that make up this firm (departments, sections, work teams, and } \\
\text { individuals) are well aware of how they contribute to achieving the overall } \\
\text { objectives. }\end{array}$ \\
\hline \multirow{4}{*}{$\begin{array}{l}\text { Openness } \\
\text { and } \\
\text { Experimentati } \\
\text { on (LE) }\end{array}$} & LEl & $\begin{array}{l}\text { This firm promotes experimentation and innovation as a way of improving the } \\
\text { work processes. }\end{array}$ \\
\hline & LE2 & $\begin{array}{l}\text { Experiences and ideas provided by external sources (advisors, customers, } \\
\text { training firms, etc.) are considered as useful instrument for this firm's learning. }\end{array}$ \\
\hline & LE3 & $\begin{array}{l}\text { Part of this firm's culture is that employees can express their opinions and make } \\
\text { suggestions regarding the procedures and methods in place for carrying out } \\
\text { tasks. }\end{array}$ \\
\hline & LE4 & $\begin{array}{l}\text { Initiative often receives a favorable response here so people feel encouraged } \\
\text { to generate new ideas. }\end{array}$ \\
\hline \multirow[t]{3}{*}{ Dialog (LD) } & LD1 & There is a free and open communication between employees. \\
\hline & LD2 & Managers facilitate communication. \\
\hline & LD3 & Cross-functional teamwork is a common practice here. \\
\hline \multirow{5}{*}{$\begin{array}{l}\text { Organization } \\
\text { al Business } \\
\text { Performance } \\
\text { (OBP) }\end{array}$} & $\mathrm{OBP} 1$ & We have enhanced return on investment, for the past few years. \\
\hline & OBP2 & We have enhanced sales and profitability of the firm, for the past few years. \\
\hline & OBP3 & For the past few years, we have been profitable. \\
\hline & OBP4 & For the past few years, we have achieved profit objectives. \\
\hline & OBP5 & For the past few years, we have achieved market share objectives. \\
\hline Firm size & FS & Total number of firm's employees (standardized value) \\
\hline
\end{tabular}

Source: Authors' work

Statistical methods

Data collected were analyzed using structural equation modeling (SEM) following six stages suggested by Hair et al. (2010). 
First, individual constructs were defined, i.e., dimensions and indicators of measurement models and theoretical definition of constructs. The second step was a development of measurement models, which means the specification of links between dimensions and indicators in order to form measuring constructs. These two steps are carried out together because the indicators and theoretical definitions were adopted from the literature. Third, sampling and determination of an adequate sample size, as well as proper identification of the model to meet the order and rank conditions were conducted. The fourth step was an estimation of the reliability and validity of measurement models using Confirmatory Factor Analysis (CFA).

Content validity has been provided by using items adapted from previous studies and by employing a panel of six experts to check the questionnaire. Furthermore, convergent validity was tested by checking the value of standardized factor loading estimates (>0.7) and Average Variance Extracted (AVE) value (>0.5). Discriminate validity was tested comparing square root values of AVE with correlation values of a specific variable with all other variables. Fifth, the specification of the structural model was conducted based on the literature review on relationships between observed constructs. Sixth step was estimation of the structural model using the Goodness of Fit (GoF) indices: $X 2 / d f \quad(<5)$, standardized root mean residual $(S R M R<0.1)$, root-mean-square-error (RMSEA <0.08), comparative-fit index (CFI>0.9), normed-fit index (NFI>0.95) Hair et al. (2010).

\section{Results and Discussion}

\section{Validity Analysis}

In order to test the hypotheses, three conceptual models are proposed. The first one with hypotheses $\mathrm{H} 1, \mathrm{H} 2$, and $\mathrm{H} 3$, which address the relationship between $\mathrm{OL}$ capability and KM capability as well as their impact on organizational business performance. Second model deals with hypotheses $\mathrm{Hla}, \mathrm{HI}, \mathrm{HlC}, \mathrm{Hld}$, i.e., the relationship between individual constructs of $\mathrm{OL}$ capability and KM capability. Finally, the third model consists of $\mathrm{Hla}, \mathrm{Hlb}, \mathrm{HlC}, \mathrm{Hld}, \mathrm{H} 4 \mathrm{a}$, and $\mathrm{H} 4 \mathrm{~b}$. SPSS 22 and Lisrel 8.8 have been used for data analysis.

Prior to models testing, Confirmative Factor Analysis (CFA) has been used in order to assess the required psychometric properties for validity and reliability and establish its usefulness for later investigations. All Goodness of Fit (GoF) indices are above/below threshold values which indicates a good fit for all measurement models, i.e., $X 2 / d f<5$; RMSEA<0.1; SRMR<0.8; CFI $>0.9 ; \mathrm{NFI}>0.95$.

Furthermore, Cronbach's alpha for all measuring models and CR values are above 0.7 confirming the reliability of the constructs. In regards to validity, convergent and discriminant, validities have been assessed. Standardized loadings of all indicators are above 0.7, which together with AVE values of constructs that are above 0.5 implies convergent validity. Finally, we have Cronbach's alpha values for each factor with its correlations with all other factors appearing in the research. Discriminant validity holds if Cronbach's alpha is greater than any of the correlations (Lloria et al., 2014; Chiva et al., 2007). 
Table 2

Validity testing

\begin{tabular}{|c|c|c|c|c|c|}
\hline Item & $\begin{array}{c}\text { Standardized factor } \\
\text { loadings }\end{array}$ & t-values & $\begin{array}{l}\text { Cronbach's } \\
\text { alpha }\end{array}$ & $C R$ & AVE \\
\hline KMA1 & 0.742 & - & 0.880 & 0.886 & 0.609 \\
\hline KMA2 & 0.759 & 15.140 & & & \\
\hline KMA3 & 0.816 & 16.354 & & & \\
\hline KMA4 & 0.825 & 16.557 & & & \\
\hline KMA5 & 0.755 & 15.053 & & & \\
\hline KMK1 & 0.871 & - & 0.939 & 0.939 & 0.794 \\
\hline KMK2 & 0.895 & 25.567 & & & \\
\hline KMK3 & 0.936 & 28.039 & & & \\
\hline KMK4 & 0.861 & 23.636 & & & \\
\hline KMP1 & 0.846 & - & 0.901 & 0.903 & 0.700 \\
\hline KMP2 & 0.794 & 18.806 & & & \\
\hline KMP3 & 0.859 & 21.204 & & & \\
\hline KMP4 & 0.847 & 20.770 & & & \\
\hline LM1 & 0.907 & - & 0.906 & 0.907 & 0.764 \\
\hline LM2 & 0.872 & 24.434 & & & \\
\hline LM3 & 0.842 & 22.925 & & & \\
\hline LV1 & 0.784 & - & 0.909 & 0.911 & 0.720 \\
\hline LV2 & 0.889 & 19.937 & & & \\
\hline LV3 & 0.879 & 19.653 & & & \\
\hline LV4 & 0.837 & 18.480 & & & \\
\hline LE1 & 0.764 & - & 0.854 & 0.861 & 0.607 \\
\hline LE2 & 0.771 & 15.844 & & & \\
\hline LE3 & 0.794 & 16.397 & & & \\
\hline LE4 & 0.787 & 16.224 & & & \\
\hline LD1 & 0.857 & - & 0.884 & 0.893 & 0.735 \\
\hline LD2 & 0.919 & 24.189 & & & \\
\hline LD3 & 0.792 & 19.287 & & & \\
\hline OBP 1 & 0.616 & - & 0.892 & 0.896 & 0.636 \\
\hline OBP2 & 0.794 & 12.762 & & & \\
\hline OBP3 & 0.793 & 12.745 & & & \\
\hline OBP4 & 0.889 & 13.713 & & & \\
\hline OBP5 & 0.868 & 13.532 & & & \\
\hline
\end{tabular}

Source: Authors' work

Table 3

Correlation between constructs and discriminant validity testing

\begin{tabular}{|c|c|c|c|c|c|c|c|c|}
\hline Dimensions & KMA & KMK & KMP & LM & LV & LE & LD & OBP \\
\hline Knowledge Acquisition (KMA) & 0.880 & & & & & & & \\
\hline Knowledge Conversion (KMK) & 0.794 & 0.939 & & & & & & \\
\hline Knowledge Application (KMP) & 0.740 & 0.660 & 0.901 & & & & & \\
\hline Managerial Commitment (LM) & 0.635 & 0.514 & 0.568 & 0.906 & & & & \\
\hline Shared Vision (LV) & 0.665 & 0.543 & 0.679 & 0.596 & 0.909 & & & \\
\hline Openness and Experimentation (LE) & 0.741 & 0.661 & 0.729 & 0.778 & 0.738 & 0.854 & & \\
\hline Dialog (LD) & 0.657 & 0.569 & 0.663 & 0.648 & 0.741 & 0.842 & 0.884 & \\
\hline Organizational Business Performance (OBP) & 0.446 & 0.331 & 0.450 & 0.402 & 0.470 & 0.475 & 0.441 & 0.892 \\
\hline
\end{tabular}

Note: Cronbach alpha values are depicted on diagonal while below are presented Cronbach alpha values derived from a CFA model of all dimensions.

Source: Authors' work 


\section{Hypotheses testing}

Following confirmation of overall fit as well as reliability and validity of measurement models, Structural Equation Modelling (SEM) is utilized in order to test structural model proposed within this study. Results revealed acceptance of two hypotheses. Specifically, OL capability positively influences $K M$ capability $(\beta=0.862 ; t=12.250$; $p<0.01)$ and organizational business performance $(\beta=0.410 ; t=3.171 ; p<0.01)$. However, this study failed to prove the significant relationship between KM capability and organizational business performance. This result could not be considered as unexpected. Many previous studies analyzed mediating and moderating effect of other organizational capabilities between KM and business performance. In other words, knowledge management should create additional value that will result in better business performance. Specifically, KM capability could enhance firm's innovation (Ju et al., 2006; Lai et al., 2012), while innovation has a positive impact on business performance (Calantone et al., 2002; Kyrgidou et al., 2012). The proposed model fits the data and all the indices are within the required values $(x 2 / \mathrm{df}=2.54$; RMSEA=0.0620; SRMR=0.0483; $C F I=0.985 ; N F I=0.974)$.

Table 4

Hypotheses Testing

\begin{tabular}{lcccc}
\hline \multicolumn{1}{c}{ Hypotheses } & St. loadings & †-values & $\mathbf{R}^{\mathbf{2}}$ & Result \\
\hline H1. OL capability $\rightarrow$ KM capability & 0.862 & $12.250^{* * *}$ & 0.744 & Supported \\
H2. OL capability $\rightarrow$ OBP & 0.410 & $3.171^{* * *}$ & 0.271 & Supported \\
H3. KM capability $\rightarrow$ OBP & 0.123 & 0.972 & 0.271 & Rejected \\
Fit indices for the research model: & & & \\
X2/df=2.54; RMSEA=0.0620; SRMR=0.0483; CFI=0.985; NFI=0.974 & & \\
\hline
\end{tabular}

Note: ${ }^{* * *} \mathrm{p}<0.01 ;{ }^{* *} \mathrm{p}<0.05 ;{ }^{*} \mathrm{p}<0.1$

Source: Authors' work

Firm's size as the control variable is included in the model and the findings didn't reveal its impact on OBP (FS $\rightarrow$ OBP: $\beta=0.067, t=1.451, p>0.1)$. This means that the firms' size in the model has no significant contribution in explaining organizational business performance.

In addition, with the aim to clarify the nature of the relationships between $\mathrm{OL}$ and KM capability and to offer practical implication for managers regarding OL activities and dimensions that should be more encouraged to improve the KM capability, the relationship between the individual dimensions of OL and KM capability is analyzed. Results revealed acceptance of two hypotheses.

Specifically, shared vision positively influence KM capability $(\beta=0.262 ; t=3.992$; $p<0.01$ ) and openness and experimentation is positively associated with the $K M$ capability $(\beta=0.564 ; t=4.479 ; p<0.01)$. That is, gathering of all employees around $a$ common identity and a shared vision as well as organizational culture that promote acceptance of new ideas and attitudes as well as tolerance of ambiguity, uncertainty and errors will results in better KM processes of acquisition, conversion and application of knowledge. 
Table 5

Hypotheses Testing

\begin{tabular}{lcccc}
\multicolumn{1}{c}{ Hypotheses } & St. loadings & t-values & $\mathbf{R}^{\mathbf{2}}$ & Result \\
\hline Hla. LM $\rightarrow$ KM capability & 0.062 & 0.883 & 0.712 & Rejected \\
HIb. LV $\rightarrow$ KM capability & 0.262 & $3.992^{* * *}$ & 0.712 & Supported \\
Hlc. LE $\rightarrow$ KM capability & 0.564 & $4.479^{* * *}$ & 0.712 & Supported \\
Hld. LD $\rightarrow$ KM capability & 0.020 & 0.218 & 0.712 & Rejected
\end{tabular}

Fit indices for the research model:

$\mathrm{x} 2 / \mathrm{df}=2.78 ; \mathrm{RMSEA}=0.0666 ; \mathrm{SRMR}=0.0449 ; \mathrm{CFI}=0.986 ; \mathrm{NFI}=0.977$

Note: ${ }^{* * *} \mathrm{p}<0.01 ;{ }^{* *} \mathrm{p}<0.05 ;{ }^{*} \mathrm{p}<0.1$

Source: Authors' work

Firm's size as the control variable is added to the model and the findings did not reveal its impact on KM (FS $\rightarrow$ KM capability: $\beta=0.033, t=0.943, p>0.1)$. This means that the firms' size in the model has no significant contribution in explaining knowledge management capability.

However, managerial commitment, as well as dialog, did not appear to have a significant impact on KM capability. Specifically, management attitudes that promote and motivate learning and communication among employees does not have a significant impact on the KM processes. Possible reasoning for the results lies in the fact that other organizational processes can moderate the relationship between the two activities and KM capability in order to strengthen these relationships. Thus, for example, HRM could facilitate organizational learning activities in order to strengthen the relationship between OL and KM capability. In order to understand the obtained result from a conceptual perspective, it is conducive to analyze the theoretical definition of the analyzed concepts. Thus, if management promotes individual learning, it would not significantly influence KM capability. The rationale for this result could be found in the logic that individual knowledge could be beneficial only if expressed and used in the organization. In addition, communication and dialogue among employees can be beneficial for KM processes if it creates some additional value, i.e., if employees communicate with the intention to share their knowledge and help others to learn. In other words, these processes could be beneficial if shared vision among employees is achieved. Consequently, $\mathrm{H} 4$ will be analyzed.

Table 6

Hypotheses Testing

\begin{tabular}{lcccc}
\hline \multicolumn{1}{c}{ Hypotheses } & St. loadings & t-values & R & Result \\
\hline Hla. LM $\rightarrow$ KM capability & 0.052 & 0.709 & 0.711 & Rejected \\
H1b. LV $\rightarrow$ KM capability & 0.295 & $4.505^{* * *}$ & 0.711 & Supported \\
Hlc. LE $\rightarrow$ KM capability & 0.576 & $4.408^{* * *}$ & 0.711 & Supported \\
Hld. LD $\rightarrow$ KM capability & -0.007 & -0.064 & 0.711 & Rejected \\
H4a. LM $\rightarrow$ LV & 0.194 & $3.521^{* * *}$ & 0.592 & Supported \\
H4b. LD $\rightarrow$ LV & 0.630 & $10.123^{* * *}$ & 0.592 & Supported \\
Fit indices for the research model: & & & \\
X2/df=2.81; RMSEA=0.0670; SRMR=0.0455; CFI=0.985; NFI=0.977 & & \\
\hline Note: ${ }^{* * *}$ P<0.01; **p<0.05; *p<0.1 & & & \\
Source: Authors' work & & &
\end{tabular}


Table 7 presents the total, indirect and direct effects in the model. A significant indirect effect enfolds that a significant amount of the independent variable's total effect on the dependent variable occurs via the mediator (Lin et al., 2008). In this sense, shared vision represents a mediator in the relationship between managerial commitment and knowledge management capability, as well as between dialogue and knowledge management capability. In other words, the LM and LD influence KM capability over LV. In addition, we have conducted Sobel's test (Sobel, 1982) for both indirect relationships. The Sobel's test determines to test for the statistical significance of the indirect effects (Santos-Vijande et al., 2012). The indirect effect in the relationship LM $\rightarrow$ LV $\rightarrow$ KM capability, is found to be statistically significant (tvalue $=2.778 ; p<0.05)$. The second indirect effect considered LD $\rightarrow L V \rightarrow K M$ capability was also significant ( $t$-value $=4.222 ; \mathrm{p}<0.05$ ). The Sobel test thus confirms that shared vision significantly mediates the effect of managerial commitment and dialogue on knowledge management capability.

Table 7

Decomposition of Effects

\begin{tabular}{|c|c|c|c|c|c|c|}
\hline \multirow[t]{2}{*}{ Path } & \multicolumn{3}{|c|}{ Unstandardized coefficients (t-values) } & \multicolumn{3}{|c|}{ Standardized coefficients } \\
\hline & Total Effect & Direct Effect & Indirect Effect & $\begin{array}{l}\text { Total } \\
\text { Effect }\end{array}$ & $\begin{array}{l}\text { Direct } \\
\text { Effect }\end{array}$ & $\begin{array}{c}\text { Indirect } \\
\text { Effect }\end{array}$ \\
\hline Hla. LM $\rightarrow$ KM capability & $0.091(1.493)$ & 0.0435 (0.709) & $0.048\left(2.816^{* * *}\right)$ & 0.109 & 0.052 & 0.057 \\
\hline H1b. LV $\rightarrow$ KM capability & $0.245\left(4.505^{* * *}\right)$ & $0.245\left(4.505^{* * *}\right)$ & & 0.295 & 0.295 & \\
\hline Hlc. LE $\rightarrow$ KM capability & $0.482\left(4.408^{* * *}\right)$ & $0.482\left(4.408^{* * *}\right)$ & & 0.576 & 0.576 & \\
\hline Hld. LD $\rightarrow$ KM capability & $0.157\left(1.871^{*}\right)$ & $-0.006(-0.064)$ & $0.163\left(4.232^{* * *}\right)$ & 0.179 & -0.007 & 0.186 \\
\hline H4a. LM $\rightarrow$ LV & $0.196\left(3.521^{* * *}\right)$ & $0.196\left(3.521^{* * *}\right)$ & & 0.194 & 0.194 & \\
\hline H4b. LD $\rightarrow$ LV & $0.667\left(10.123^{* * *}\right)$ & $0.667\left(10.123^{* * *}\right)$ & & 0.630 & 0.630 & \\
\hline
\end{tabular}

Note: ${ }^{* * *} p<0.01 ;{ }^{* *} p<0.05 ;{ }^{*} p<0.1$

Source: Authors' work

The results of Preacher et al. (2004) PROCESS procedure for "model 4" imply that shared vision is significant mediator in driving the effect of managerial commitment on knowledge management capability $(\beta=0.251, C l=(0.176,0.338))$ and the effect of dialogue on KM capability $(\beta=0.241, C l=(0.164,0.323))$.

The main goal of this paper was to analyze the empirical relationship between OL dimensions and KM capability. In the light of this goal and as a concluding remark, the results obtained indicate the links between the dimensions of $\mathrm{OL}$ and $\mathrm{KM}$ as shown in Figure 2.

Figure 2

The relationship between $\mathrm{OL}$ dimensions and KM supported by the findings

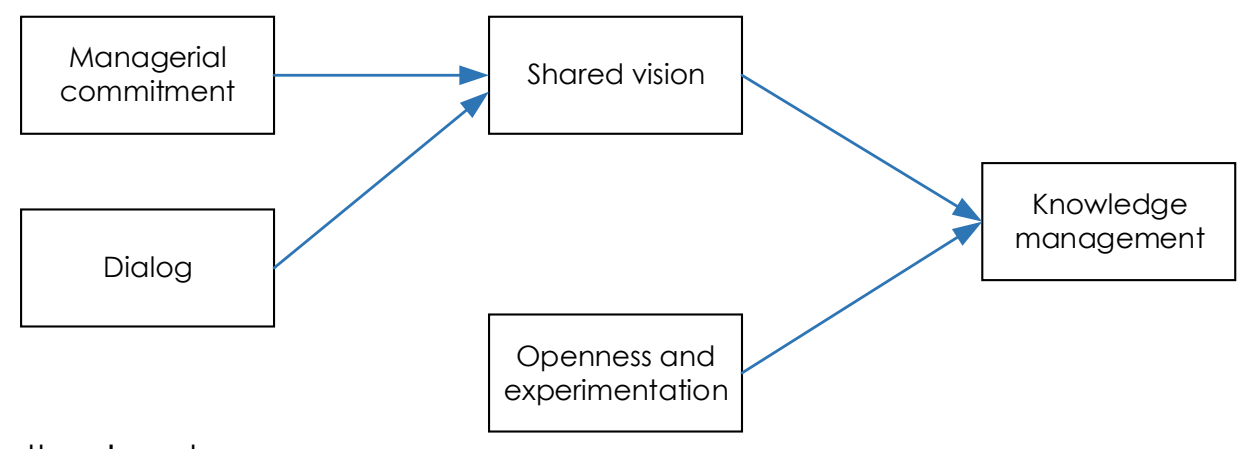

Source: Authors' work 


\section{Conclusion}

The paper aimed at analyzing the relations between organizational learning capability and knowledge management capability. In this respect, the theoretical foundation identified is organization theory revealing the principles that govern organizations' processes. The results confirm that OL dimensions are antecedents of knowledge management capability. Shared values and openness influence directly and positively KM capability. However, the same was not found to be the case for managerial commitment and dialogue. However, the results suggest that managerial commitment and dialog influence KM capability indirectly over shared vision. In other words, while KMC is directly affected by LV and LE, contrary to our expectations, the results indicated that LM and LD do not exert a significant direct effect on KMC but require the mediating effect of LV. This practically means that firms can enhance their KM processes through promoting of innovation and experimentation as a way of improving the business activities and through the consideration of experiences and ideas provided by external sources as useful instruments for firm's learning. In addition, firm's culture that promotes expression of opinion among employees would be beneficial for the improvement of KM capability. Similarly, a unique understanding of organizational vision through all levels, functions, and divisions, as well as the dedication of employees' to the organization's goals would have a positive impact on organizational KM. In addition, if employees consider themselves as partners in mapping the direction of the organization's actions and are aware of how they contribute to achieving the overall objectives, it will enhance KM processes. In order to achieve an understanding of organizational vision among employees and their commitment, management should promote individual learning, encourage, and facilitate communication and dialogue. The results concordance findings of Noruzy et al. (2013) who confirmed that organizational learning directly and positively influenced knowledge management and organizational performance.

In addition, drawing on with the dynamic capability view, relationships between organizational learning, knowledge management, and organizational business performance were analyzed. The results show that $\mathrm{OL}$ capability positively influences KM capability and organizational business performance. However, knowledge management capability did not appear to have a significant positive influence on organizational business performance. Similarly, Darroch (2005) didn't find sufficient arguments to support the premise that firms with well-developed knowledge management practices would perform better and concluded that firms with higher KM capability are more likely to develop incremental innovations. In other words, it is more likely that KM influences organizational business performance indirectly, over other dynamic capabilities. Noruzy et al. (2013) that found knowledge management affected organizational performance indirectly through organizational innovation as well.

The study provides advances in the field of organizational learning and knowledge management literature by offering empirical analysis that confirms the importance of individual constructs of organizational learning capability for successful knowledge management. While there has been an underlying assumption about the role of organizational learning for knowledge management, this study provides evidence on how $\mathrm{OL}$ dimensions such as management commitment, shared vision, openness and experimentation, and dialog may be adjusted to facilitate and promote the enhancement of KM processes. Contrary to previous studies, this paper presents an analysis of simultaneous impacts of a set of OL practices on KM capability. First, firms must support individual learning and 
encourage dialogue as a necessary requisite to obtaining shared vision among employees. Achieving shared vision becomes a vital capability that together with openness and experimentation enhance knowledge management. Besides, organizational learning capability directly influences organizational business performance. The study is cross-sectional, and the data are collected in a single transitional economy country, which can be considered the main limitation of the study. Future research should include in the model capabilities that drive the effect of KM capability on organizational business performance.

In spite of the implications, this study has several limitations that the interpretation of the results should take into consideration. First, the results of this survey were limited to $\mathrm{BH}$ firms. Although this study has the contribution to the analysis of the observed constructs on the example of a transitional economy, future research should test the OL-KM model in developed and other transitional countries. Second, utilizing crosssectional research with questionnaires is also one of the limitations of this study. Future research may overcome this limitation involving longitudinal studies in which $\mathrm{KM}$ and $\mathrm{OL}$ can be followed over time. Third, using objective measures may give results that are more objective, especially in organizational performance. Finally, future research should test the proposed conceptual model considering the specificities of different industries, which is not the subject of an analysis of this paper.

\section{References}

1. Akgun, A. E., Keskin, H., Byrne, J. C., Aren, S. (2007), "Emotional and learning capability and their impact on product innovativeness and firm performance", Technovation, Vol. 27, No. 9, pp. 501-513.

2. Alegre, J., Chiva, R. (2008), "Assessing the impact of organizational learning capability on product innovation performance: An empirical test", Technovation, Vol. 28, No. 6, pp. $315-$ 326.

3. Alegre, J., Chiva, R. (2013), "Linking entrepreneurial orientation and firm performance: The role of organizational learning capability and innovation performance", Journal of Small Business Management, Vol. 51, No. 4, pp. 491-507.

4. Apak, S., Tuncer, G., Atay, E., Koşan, N. I. (2012), "Insights From Knowledge Management to Radical Innovation: "Internet Banking Applications in the European Union", Procedia Social and Behavioral Sciences, Vol. 41, pp. 45-50.

5. Barney, J. (1991), "Firm Resources and Sustained Competitive Advantage", Journal of Management, Vol. 17, No. 1, pp. 99-120.

6. Calantone, R. J., Cavusgil, S. T., Zhao, Y. (2002), "Learning Orientation, Firm Innovation, and Firm Performance", Industrial Management \& Data Systems, Vol. 31, No. 6, pp. 515-524.

7. Celemín-Pedroche, M. S., Rubio-Andrada, L., Rodríguez-Antón, J. M., Alonso-Almeida, M. D. M. (2017), "Causal relationships between organisational learning and performance in the Spanish hotel industry: the managers' perception in times of economic crisis", International Journal of Innovation and Learning, Vol. 21, No. 3, pp. 274-298.

8. Chen, J. S., Tsou, T. T., Huang, A. Y. H. (2009), "Service Delivery Innovation: Antecedents and Impact on Firm Performance", Journal of Service Research, Vol. 12, No. 1, pp. 36-55.

9. Chen, L., Fong, P. S. W. (2013), "Visualizing Evolution of Knowledge Management Capability in Construction Firms", Journal of Construction Engineering and Management, Vol. 139, No. 7, pp. 839-851.

10.Chiva, R., Alegre, J., Lapiedra, R. (2007), "Measuring organisational learning capability among the workforce", International Journal of Manpower, Vol. 28, No. 3/4, pp. 224-242.

11.Chuang, S.-H., Liao, C., Lin, S. (2013), "Determinants of knowledge management with information technology support impact on firm performance", Information Technology and Management, Vol. 14, No. 3, pp. 217-230.

12.Cui, A. S., Griffith, D. A., Cavusgil, S. T. (2005), "The Influence of Competitive Intensity and Market Dynamism on Knowledge Management Capabilities of Multinational Corporation Subsidiaries", Journal of International Marketing, Vol. 13, No. 3, pp. 32-53. 
13.Cycyota, C. S., Harrison, D. A. (2002), "Top Manager Responses to Organisational Surveys: When Questioning Executives, Are Networks The Answer?", Academy of Management Proceedings.

14.Darroch, J. (2005), "Knowledge management, innovation and firm performance", Journal of Knowledge Management, Vol. 9, No. 3, pp. 101-115.

15.Davenport, T. H., Prusak, L. (1997). Information ecology: Mastering the information and knowledge environment, Oxford University Press on Demand.

16.Dayan, R., Heisig, P., Matos, F. (2017), "Knowledge management as a factor for the formulation and implementation of organization strategy", Journal of Knowledge Management, Vol. 21, No. 2, pp. 273-298.

17.Donate, J. M., Guadamillas, F. (2011), "Organizational factors to support knowledge management and innovation", Journal of Knowledge Management, Vol. 15, No. 6, pp. 890-914.

18.Grant, R. (1996), "Toward a knowledge based theory of the firm", Strategic Management Journal, Vol. 17, No. S2, pp. 109-122.

19.Hair, J. F. Jr., Black, W. C., Babin, B. J., Anderson, R. E. (2010). Multivariate Data Analysis, Pearson Prentice Hall.

20.Hatch, M. J., Cunliffe, A. L. (2013). Organization Theory: modern, symbolic and postmodern perspective, Oxford, University Press, UK.

21.Hodgkinson, M. (2002), "A shared strategic vision: dream or reality?", The Learning Organization, Vol. 9, No. 2, pp. 89-95.

22.Jerez-Gómez, P., Céspedes-Lorente, J., Valle-Cabrera, R. (2005), "Organizational learning capability: A proposal of measurement", Journal of Business Research, Vol. 58, No. 6, pp. 715-725.

23.Ju, T. L., Li, C. Y., Lee, T. S. (2006), "A contingency model for knowledge management capability and innovation", Industrial Management \& Data Systems, Vol. 106, No. 6, pp. 855-877.

24.Kyrgidou, L. P., Spyropoulou, S. (2012), "Drivers and Performance Outcomes of Innovativeness: An Empirical Study", British Journal of Management, Vol. 24, No. 3, pp. 281298.

25.Lai, Y., Lin, F. (2012), "The Effects of Knowledge Management and Technology Innovation on New Product Development Performance - An Empirical Study of Taiwanese Machine Tools Industry", Procedia - Social and Behavioral Sciences, Vol. 40, pp. 157-164.

26.Liao, S., Wu, C. C. (2009), "The relationship among knowledge management, organizational learning, and organizational performance", International Journal of Business and Management, Vol. 4, No. 4, pp. 64-76.

27.Lin, C. H., Peng, C. H., Kao, D. T. (2008), "The innovativeness effect of market orientation and learning orientation on business performance", International Journal of Manpower, Vol. 29, No. 8, pp. 752-772.

28.Lloria, M. B., Moreno-luzon, M. D. (2014), "Organizational learning: Proposal of an integrative scale and research instrument", Journal of Business Research, Vol. 67, No. 5, pp. 692-697.

29.Lockett, A., Thompson, S., Morgenstern, U. (2009), "The development of the resourcebased view of the firm: A critical appraisal", International Journal of Management Reviews, Vol. 11, No. 1, pp. 9-28.

30.López-Cabrales, Á., Real, J. C., Valle, R. (2011), "Relationships between human resource management practices and organizational learning capability: The mediating role of human capital", Personnel Review, Vol. 40, No. 3, pp. 344-363.

31.Martinez-Conesa, I., Soto-Acosta, P., Carayannis, E. G. (2017), "On the path towards open innovation: Assessing the role of knowledge management capability and environmental dynamism in SMEs", Journal of Knowledge Management, Vol. 21, No. 3, pp. 553-570.

32.McKeown, I., Philip, G. (2003), "Business transformation, information technology and competitive strategies: Learning to fly", International Journal of Information Management, Vol. 23, No. 1, pp. 3-24.

33.McKinley, W., Mone, M., Moon, G. (1999), "Determinants and devopment of schools in organization theory", Academy of Management Review, Vol. 24, No. 4, pp. 634-648. 
34.Nezam, M. H. K., Ataffar, A., Isfahani, A. N., Shahin, A. (2016), "Human capital and new product development performance efficiency-the mediating role of organisational learning capability", International Journal of Innovation and Learning, Vol. 20, No. 1, pp. 26-46.

35.Noruzy, A., Dalfard, V. M., Azhdari, B., Nazari-Shirkouhi, S., Rezazadeh, A. (2013), "Relations between transformational leadership, organizational learning, knowledge management, organizational innovation, and organizational performance: an empirical investigation of manufacturing firms", International Journal of Advanced Manufacturing Technology, Vol. 64, No. 5-8, pp. 1073-1085.

36.Preacher, K. J., Hayes, A. F. (2004), "SPSS and SAS procedures for estimating indirect effects in simple mediation models", Behavior research methods, instruments, \& computers, Vol. 36, No. 4, pp. 717-731.

37.Prieto, I. M., Pérez-Santana, M. P. (2014), "Managing innovative work behavior: the role of human resource practices", Personnel Review, Vol. 43, No. 2, pp. 184-208.

38.Pun, K. F., Nathai-Balkissoon, M. (2011), "Integrating knowledge management into organisational learning", The Learning Organization, Vol. 18, No. 3, pp. 203-223.

39. Qi, C., Chau, P. Y. K. (2018), "Will enterprise social networking systems promote knowledge management and organizational learning? An empirical study", Journal of Organizational Computing and Electronic Commerce, Vol. 28, No. 1, pp. 31-57.

40.Sailer, K., Penn, A. (2010), "Towards an Architectural Theory of Space and Organisations: Cognitive", Affective and Conative Relations in Workplaces', 2nd Workshop on Architecture and Social Architecture, EIASM, Brussels, pp. 1-16.

41.Santos-Vijande, M. L., Lopez-Sanchez, J. A., Gonzales-Mieres, C. (2012), "Organizational Learning, Innovation, and Performance in KIBS", Journal of Management \& Organization, Vol. 18, No. 6, pp. 870-904.

42.Sobel, E. (1982), "Asymptotic confidence intervals for indirect effects in structural equation models", in Leinhart, S. (Ed.), Sociological methodology, Jossey-Bass, San Francisco, pp. 290-312.

43.Tanriverdi, H. (2011), "Information Technology Relatedness, Management Knowledge Capability, of multibusiness performance", MIS Quarterly, Vol. 29, No. 2, pp. 31 1-334.

44.Teece, D. J., Pisano, G., Shuen, A. (1997), "Dynamic Capabilities and Strategic Management David", Strategic Management Journal, Vol. 18, No. 7, pp. 509-533. 


\section{About the authors}

Lejla Turulja is an Assistant Professor at the Department of Management and Information Technology of the School of Economics and Business Sarajevo, University of Sarajevo. She is USA State Department Professional Fellow for 2017. Her main research interests are information technology management, technology transfer, innovation, knowledge management, innovation management, HR and KM information systems, e-business. She was actively engaged in number of science projects. Lejla Turulja published several scientific papers in recognized journals and participated in many scientific international conferences. Also, she is a reviewer for several international peer-review journals. The author can be contacted at lejla.turulja@efsa.unsa.ba

Nijaz Bajgoric is a Professor of Business Computing and Information Technology Management at the School of Economics and Business Sarajevo, B\&H. He has a PhD from the University of Sarajevo. He teaches and conduct research in information technology, business computing, information technology management and operating systems. He has published papers in the following peer-reviewed journals: International Journal of Enterprise Information Systems, Kybernetes, Information Management and Computer Security, Information Systems Management, Industrial Management and Data Systems etc., and has authored and co-authored chapters in the edited books published by: Elsevier Science, Kluwer Academic Publisher, CRC Press and Auerbach Publications. Author can be contacted at nijaz.bajgoric@efsa.unsa.ba. 